\title{
Acute Dose-Related Differential Effects of Methylphenidate on Murine Cystometric Parameters
}

\author{
Sung Ho Choi, Young Sam Cho, Sung Tae Cho ${ }^{1}$, Tack Lee², Khae Hawn Kim³ \\ Department of Urology, Kangbuk Samsung Hospital, Sungkyunkwan University School of Medicine, Seoul; \\ ${ }^{1}$ Department of Urology, Hallym University Kangnam Sacred Heart Hospital, Hallym University College of Medicine, Seoul; \\ ${ }^{2}$ Department of Urology, Inha University Hospital, Inha University School of Medicine, Incheon; \\ ${ }^{3}$ Department of Urology, Gachon University Gil Medical Center, Gachon University Medicine and Science, Incheon, Korea
}

Purpose: Methylphenidate is the most widely used central nervous system stimulant in patients with attention deficit hyperactivity disorder. However, few studies have assessed its effects on voiding. Various doses of methylphenidate were investigated for their effects on cystometric parameters in conscious mice.

Methods: Ten male C57BL/6 mice, weighing between 20 and $23 \mathrm{~g}$, were used in this study. To compare the acute drug responses before and after the oral medication was administered in the awake condition, we injected the solution through a catheter inserted into the stomach. Methylphenidate $(1.25,2.5$, and $5 \mathrm{mg} / \mathrm{kg})$ in an injection volume of $0.05 \mathrm{~mL}$ was administered.

Results: Four mice that received high doses of methylphenidate $(2.5$ and $5 \mathrm{mg} / \mathrm{kg})$ showed no voiding contraction, with urine leakage. Six mice that received a low dose of methylphenidate $(1.25 \mathrm{mg} / \mathrm{kg})$ showed typical micturition cycles before and after administration. The micturition pressure decreased and bladder capacity increased without an increased residual volume after administration.

Conclusions: Methylphenidate has differential, dose-dependent effects on the function of the lower urinary tract, due to the dependent relationship between the brain and lower urinary tract. Especially at higher doses, this drug may interfere with normal micturition. Therefore, more detailed clinical or experimental studies are warranted in the future.

Keywords: Methylphenidate; Attention deficit disorder with hyperactivity; Urodynamics; Mice; Neurogenic urinary bladder

\section{INTRODUCTION}

Methylphenidate is recommended as the first-line medication for attention deficit hyperactivity disorder (ADHD), and is believed to affect certain metabolic mechanisms of the central nervous system (CNS) [1]. Methylphenidate is widely prescribed as a CNS stimulant and its use has increased in recent years as the diagnosis of ADHD has become more specific and reliable [2]. Recent clinical evidence indicates that this agent is effective for ADHD throughout the disease course [3,4], which usually begins in early childhood [5] and is often maintained into adulthood [6]. Despite the well-established therapeutic efficacy of methylphenidate, the mechanisms underlying its therapeutic effects and side effects remain poorly understood. Moreover, data remain limited data regarding the direct effects of methylphenidate on bladder function.

The urinary bladder and urethra, comprising the lower urinary tract, constitute a single functional unit controlled by a complex network of the CNS, peripheral nervous system, and local regulatory factors $[7,8]$. The CNS acts as a terminal switch to modulate the ensuing involuntary steps of micturition controlled by the autonomic nervous system [9]. Thus, CNS diseases such as ADHD have tended to obscure or modify the true nature of the voiding dysfunction associated with the disease. Animal studies demonstrate that methylphenidate exerts differential effects on brain function, such as stereotyped behavior, in
Corresponding author: Khae Hawn Kim

Department of Urology, Gachon University Gil Medical Center,

Gachon University of Medicine and Science, 21 Namdong-daero 774 beon-gil,

Namdong-gu, Incheon 405-760, Korea

Tel: +82-32-460-3331 / Fax: +82-32-460-8340

E-mail: kimcho99@gilhospital.com

Submitted: November 3, 2013 / Accepted after revision: November 23, 2013
This is an Open Access article distributed under the terms of the Creative Commons Attribution Non-Commercial License (http://creativecommons.org/licenses/by-nc/3.0/) which permits unrestricted non-commercial use, distribution, and reproduction in any medium, provided the original work is properly cited. 
a dose-dependent manner [10]. Because the autonomic functions of the lower urinary tract are directly dependent on brain functions $[9,11]$, animal studies of the awake responses on micturition caused by various doses of methylphenidate may lead to a better understanding of the mechanisms underlying its psychostimulatory effects.

This study aimed to investigate and compare the patterns of urodynamic changes after intragastric injection of various doses of methylphenidate in mice. Our hypothesis was that methylphenidate exerts peripheral effects on the autonomic nervous system, which are related to micturition, although the patterns of micturition differ in a dose-dependent manner.

\section{MATERIALS AND METHODS}

\section{Experimental Animals}

Ten male C57BL/6 mice, weighing between 20 and $23 \mathrm{~g}$, obtained from Orient Bio Inc. (Seongnam, Korea), were used in this study. The mice were handled under standard laboratory conditions with a 12:12-hour light:dark cycle, with free access to food pellets and tap water. All animal handling and treatment procedures were performed in accordance with the Guide for the Care and Use of Laboratory Animals of the National Institutes of Health and were approved by the Ethics Committee of the Inha University College of Medicine.

\section{Surgical Procedures}

Mice were anaesthetized with ketamine $(75 \mathrm{mg} / \mathrm{kg}$ intraperitoneally; Yuhan Co., Seoul, Korea). The bladder and urethra were approached through a lower abdominal midline incision. A polyethylene catheter (PE-10, Becton Dickinson, Parsipanny, NJ, USA) with a cuff was implanted in the dome and held in place with a purse-string suture. For drug delivery, another PE10 catheter with a cuff was introduced into the gastric body around the greater curvature of the stomach using a similar method as that employed for the bladder. Both catheters were tunneled subcutaneously and anchored to the skin of the back with a silk ligature. The free end of the catheter was sealed. After surgery, the animals were caged individually and maintained in the same manner.

\section{Cystometric Investigations}

Cystometry was performed without anesthesia 2 days after the implantation of the bladder and gastric catheters. Conscious mice were placed in mouse metabolic cages (Tecniplast, Bugug- giate, Italy) without restraints and the bladder catheter was connected via a T-tube to a pressure transducer (Research Grade Blood Pressure Transducer, Harvard Apparatus, Holliston, MA, USA) and a microinjection pump (PHD22/2000 pump, Harvard Apparatus). Micturition volumes were recorded with a fluid collector connected to a force displacement transducer (Research Grade Isometric Transducer). Room-temperature saline was infused into the bladder continuously at a rate of $2 \mathrm{~mL} / \mathrm{hr}$. Pressure and micturition volumes were recorded continuously with Acq Knowledge 3.8.1 software and an MP150 data acquisition system (Biopac Systems, Goleta, CA, USA) at a sampling rate of $100 \mathrm{~Hz}$. The mean values from three reproducible micturition cycles of each mouse from the three groups were used for the urodynamic evaluation.

The following urodynamic parameters were investigated: basal pressure (BP, the lowest bladder pressure during filling), threshold pressure (TP, bladder pressure immediately before micturition), maximal pressure (MP, maximum bladder pressure during micturition), bladder capacity (BC, residual volume at the most recent previous micturition plus the volume of infused saline at micturition), micturition volume (MV, volume of expelled urine), residual volume (RV, bladder capacity minus micturition volume), and micturition interval (MI, intercontraction interval).

\section{Drug and Administration}

Methylphenidate (Ritalin, Novartis Co., Basel, Switzerland) was dissolved in normal saline on the day of cystometry. To compare the drug responses before and after oral medication administration in the awake condition, we injected the solution directly through the catheter into the stomach. After three representative continuous micturitions were taken to establish baseline cystometric data, methylphenidate $(1.25,2.5$, and $5 \mathrm{mg} / \mathrm{kg})$ in an injection volume of $0.05 \mathrm{~mL}$ was administered via the gastric catheter, followed by $0.02 \mathrm{~mL}$ of normal saline $(0.9 \%)$. Thirty minutes after the injection, cystometry was repeated, and the results were compared with those at baseline.

\section{Statistical Analysis}

Results are given as mean \pm standard errors of the mean (SEM). Normal distributions were confirmed by the Shapiro-Wilk W test. Statistical significance was determined with paired Student t-tests when appropriate. All analyses were performed using GraphPad Prism, ver. 5.03, 2009 (Graph Pad Software, San Diego, CA, USA). Statistical significance was considered at the 
$\mathrm{P}<0.05$ level.

\section{RESULTS}

Generally, the micturition patterns of the mice were consistent and similar detailed features were observed in all micturition cycles. The representative tracings of the baseline and medicated urodynamic results are shown in Fig. 1. After the injection of methylphenidate into the gastric tube, the mice showed no features of excitation or pain related to the administration method. On the contrary, they showed more appeared more focused and calm after receiving the medication.

Four mice that received high doses of methylphenidate (2.5 and $5 \mathrm{mg} / \mathrm{kg}$ ) were excluded from the analysis of the pressure and volume parameters because they did not show the typical configurations of the micturition cycles. They showed no pressure rise representing the voiding contraction, with the urine leaking in the sitting position with eyes closed (Figs. 1C, 2).

Six mice that received a low dose of methylphenidate (1.25 $\mathrm{mg} / \mathrm{kg}$ ) showed the typical configurations of the micturition cycles before and after medication administration (Fig. 1A, B),
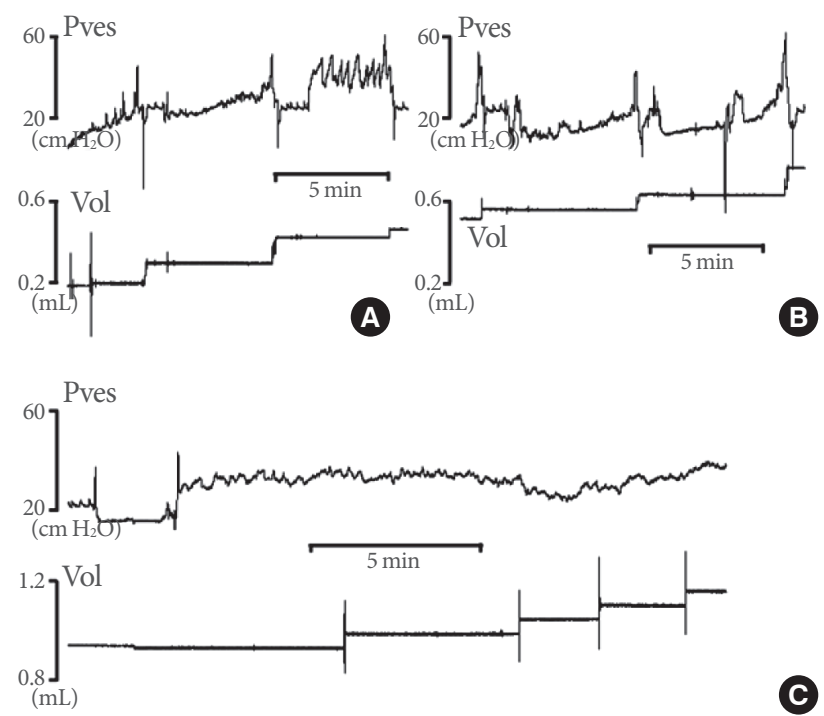

C

Fig. 1. Representative tracings showing the effects of methylphenidate injected into the gastric tube on cystometric findings. (A) Basic cystometry before methylphenidate administration. (B) Cystometric findings after administration of the lower dose of methylphenidate $(1.25 \mathrm{mg} / \mathrm{kg})$. (C) Cystometric findings after administration of the highest dose of methylphenidate $(5 \mathrm{mg} /$ $\mathrm{kg}$ ). The mice that received the highest dose showed no voiding contraction pattern and showed only continuous leakage of a small amount of urine. Pves, vesical pressure. and in these mice, the pressure and volume parameters were analyzed. There were no significant differences in BP before $\left(20.8 \pm 1.5 \mathrm{~cm} \mathrm{H}_{2} \mathrm{O}\right)$ or after $\left(18.0 \pm 3.8 \mathrm{~cm} \mathrm{H}_{2} \mathrm{O}\right)$ methylphenidate treatment. TPs $\left(37.1 \pm 4.3 \mathrm{~cm} \mathrm{H}_{2} \mathrm{O}\right)$ and MPs $(71.2 \pm 6.6$ $\left.\mathrm{cm} \mathrm{H}_{2} \mathrm{O}\right)$ significantly decreased after treatment $(30.0 \pm 4.7 \mathrm{~cm}$ $\mathrm{H}_{2} \mathrm{O}$ and $60.8 \pm 4.5 \mathrm{~cm} \mathrm{H} \mathrm{H}_{2} \mathrm{O}$, respectively). $\mathrm{BCs}(0.08 \pm 0.01 \mathrm{~mL})$, MVs $(0.08 \pm 0.01 \mathrm{~mL})$, and MIs ( $4.90 \pm 0.86$ minutes) significantly increased $(0.10 \pm 0.01,0.09 \pm 0.01$, and $5.67 \pm 0.81$, respectively), whereas the RV showed no significant difference after treatment (Fig. 3).

\section{DISCUSSION}

A functional role for methylphenidate in the lower urinary tract has not yet been established. However, the findings of a few studies suggest a possible beneficial effect of methylphenidate in the therapy of patients with voiding dysfunctions such as giggle incontinence, which improved following medication administration $[12,13]$. The urodynamic changes induced by this drug, even in those studies, have never been elucidated. The results of the present study showed that methylphenidate in lower
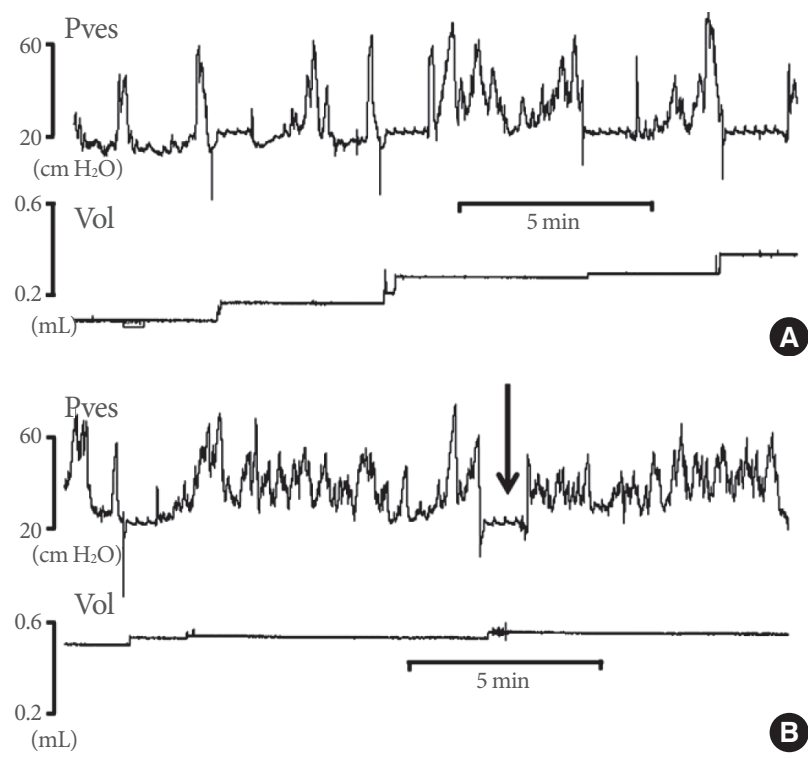

Fig. 2. Representative tracings showing the effects of methylphenidate injected into the gastric tube on cystometric findings. (A) Basic cystometry before methylphenidate admiration. (B) Cystometric findings after administration of the higher dose of methylphenidate $(2.5 \mathrm{mg} / \mathrm{kg})$. The mice that received this dose also showed no voiding contraction. There was no residual urine at the time point at which the urine leaked (arrow). Pves, vesical pressure. 

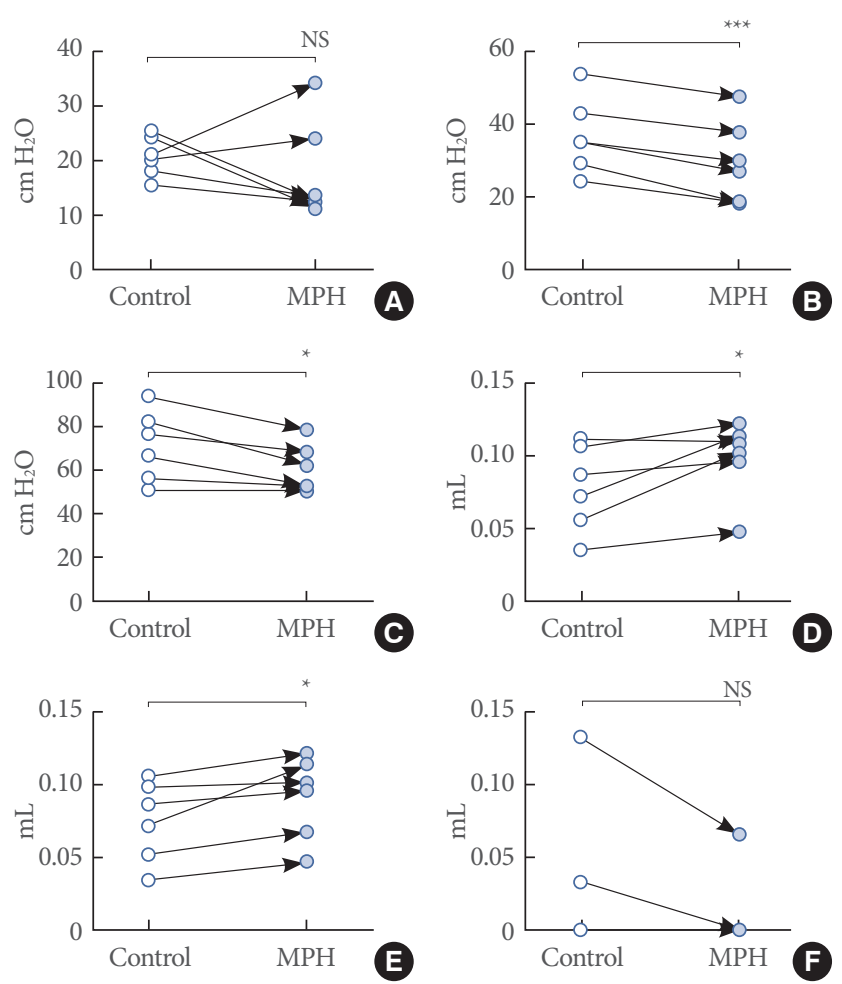

Fig. 3. Effects of lower-dose methylphenidate $(1.25 \mathrm{mg} / \mathrm{kg})$ on cystometric parameters. (A) Basal pressure. (B) Threshold pressure. (C) Micturition pressure. (D) Bladder capacity. (E) Micturition volume. (F) Residual volume. Empty and black circles indicate the values before and after methylphenidate administration. $\mathrm{MPH}$, methylphenidate; NS, not significant. ${ }^{\star} \mathrm{P}<0.05$. ${ }^{* * *} \mathrm{P}<0.001$.

doses significantly changes the urodynamic parameters related to the functions of the lower urinary tract, including the bladder and urethra. The pressure parameters decreased as the volume parameters increased, which implies that this drug improves the storage function without a detrimental effect on the voiding function. However, higher doses of this drug showed some unusual urodynamic findings; the peripheral effects seemed to be masked by the central effects.

Despite the widespread use of methylphenidate to treat $\mathrm{ADHD}$, very little is known about the mechanisms underlying the urodynamic changes related to this drug, but we can presume the nature of the mechanisms of action from an ADHD study [1416]. The frontal cortex inhibits subcortical structures via the dopaminergic and noradrenergic pathways, which enables the brain to perform attention and cognition functions and sensory signal processing [17]. Impairment of the dopaminergic tracts leading to inappropriate inhibition is the hallmark of ADHD
$[1,15]$. The main mechanism of action by which methylphenidate suppresses the symptoms of ADHD is thought to involve modulation of the catecholamines in the prefrontal cortex of the brain through binding to the dopamine transporter [13]. The prefrontal cortex is believed to be involved in goal-directed behaviors and the processes of attention, which might be involved in the determination to start the voiding process by the autonomic nervous system $[9,18]$.

The normal micturition reflex is mediated by the spinobulbospinal pathway regulated by higher brain centers such as the pontine micturition center, periaqueductal gray, and cerebral cortex $[19,20]$. During the storage phase, afferent signals from the full bladder enter the periaqueductal gray in the CNS, which controls micturition by communicating with two different regions of the pontine tegmentum, the pontine micturition center and the pontine urine storage center $[7,21,22]$. The preoptic area of the hypothalamus influences the pontine micturition center and determines the initiation of micturition. Experimental results in animals show that diencephalic dopamine-immunoreactive neurons are closely related to the ventricles in the preoptic area and hypothalamus [11]. This suggests that methylphenidate can directly influence the determination of micturition initiation. With higher doses of methylphenidate, mice showed no pressure increase of the micturition contraction in the curve of intravesical pressure, but showed urine leakage. This effect may be related to the inhibition of the start of micturition and overflow incontinence. However, with low doses of methylphenidate, the mice showed decreased TP and MP during the voiding phase, although there were no definite changes in the BP as the parameter of the storage phase. The bladder capacity was increased without an increase in the RV. This may result from the direct influence on the peripheral nervous system of the lower urinary tract.

In order to investigate the acute drug effect in mice, the most widely used method is gavage using a stomach tube. This model is comparable to the effects of oral medications in human subjects $[23,24]$. The restraint method is needed to minimize the risk of adverse effects related to this procedure. However, such restraint and other coercive acts have the possibility of causing excitation and irritation of the bladder. Cystometry provides objective information on the function of the lower urinary tract during the storage and voiding phases of the bladder cycle, using measured parameters of pressures and volumes. The pressures measured in the bladder, namely the intravesical pressures, include the true detrusor pressure and the intra-abdominal 
pressure [25]. Awake murine cystometry, performed under conscious conditions, is vulnerable to the excitation of animals, which makes it difficult to compare the parameters before and after the medication is administered. Our method of injection into the previously inserted gastric catheter seems to be a solution to this problem. Injection of the drug into the gastric tube yielded no excitation or irritation of the bladder.

Recent surveys of children with ADHD indicate higher risks of nocturnal enuresis, incontinence, urgency, infrequent voiding, dysuria, and constipation compared to those without ADHD [26,27]. Furthermore, CNS stimulants such as methylphenidate are considered to be the "Gold Standard" of medication treatment for ADHD [1,2], and most children with ADHD are first administered this medication. Thus, there is a high possibility that the dependent relationship between the brain and lower urinary tract leads to underestimation of the true incidence of voiding dysfunctions in ADHD patients treated with methylphenidate, as they may omit complaints about their voiding problems. Our study showed the possibility that methylphenidate may change voiding patterns in children with ADHD, with different voiding patterns showing different dose-response relationships. Therefore, more detailed clinical or experimental studies are warranted in the future.

Our study showed that the responses of the lower urinary tract to various dosages of methylphenidate are different, due to the peculiar control system of the lower urinary tract. These findings suggest that these characteristics can lead to underestimation of the prevalence of voiding problems. Reinvestigation of voiding patterns in children on methylphenidate is warranted, both experimentally and clinically.

\section{CONFLICT OF INTEREST}

No potential conflict of interest relevant to this article was reported.

\section{ACKNOWLEDGEMENTS}

This work was supported by the National Research Foundation of Korea Grant funded by the Korean Government (NRF2012R1A1A1013173).

\section{REFERENCES}

1. Reitz SJ. Attention-deficit/hyperactivity disorder: focus on pharma- cologic management. J Pediatr Health Care 1997;11:78-83.

2. Scheffler RM, Hinshaw SP, Modrek S, Levine P. The global market for ADHD medications. Health Aff (Millwood) 2007;26:450-7.

3. Biederman J, Spencer T, Wilens T. Evidence-based pharmacotherapy for attention-deficit hyperactivity disorder. Int J Neuropsychopharmacol 2004;7:77-97.

4. Pastor PN, Reuben CA. Diagnosed attention deficit hyperactivity disorder and learning disability: United States, 2004-2006. Vital Health Stat 10 2008;(237):1-14.

5. Zito JM, Safer DJ, dosReis S, Gardner JF, Boles M, Lynch F. Trends in the prescribing of psychotropic medications to preschoolers. JAMA 2000;283:1025-30.

6. Spencer T, Biederman J, Wilens T, Harding M, O'Donnell D, Griffin S. Pharmacotherapy of attention-deficit hyperactivity disorder across the life cycle. J Am Acad Child Adolesc Psychiatry 1996;35: 409-32.

7. Andersson KE, Wein AJ. Pharmacology of the lower urinary tract: basis for current and future treatments of urinary incontinence. Pharmacol Rev 2004;56:581-631.

8. Fowler CJ, Griffiths D, de Groat WC. The neural control of micturition. Nat Rev Neurosci 2008;9:453-66.

9. Tai C, Wang J, Jin T, Wang P, Kim SG, Roppolo JR, et al. Brain switch for reflex micturition control detected by FMRI in rats. J Neurophysiol 2009;102:2719-30.

10. Pechnick R, Janowsky DS, Judd L. Differential effects of methylphenidate and d-amphetamine on stereotyped behavior in the rat. Psychopharmacology (Berl) 1979;65:311-5.

11. Roberts BL, Meredith GE, Maslam S. Immunocytochemical analysis of the dopamine system in the brain and spinal cord of the European eel, Anguilla anguilla. Anat Embryol (Berl) 1989;180:401-12.

12. Berry AK, Zderic S, Carr M. Methylphenidate for giggle incontinence. J Urol 2009;182(4 Suppl):2028-32.

13. Chang JH, Lee KY, Kim TB, Yoon SJ, Lee T, Kim KH. Clinical and urodynamic effect of methylphenidate for the treatment of giggle incontinence (enuresis risoria). Neurourol Urodyn 2011;30:1338-42.

14. Grund T, Lehmann K, Bock N, Rothenberger A, Teuchert-Noodt G. Influence of methylphenidate on brain development: an update of recent animal experiments. Behav Brain Funct 2006;2:2.

15. Prince J. Catecholamine dysfunction in attention-deficit/hyperactivity disorder: an update. J Clin Psychopharmacol 2008;28(3 Suppl 2):S39-45.

16. Sullivan RM, Brake WG. What the rodent prefrontal cortex can teach us about attention-deficit/hyperactivity disorder: the critical role of early developmental events on prefrontal function. Behav Brain Res 2003;146:43-55. 
17. Agster KL, Clark BD, Gao WJ, Shumsky JS, Wang HX, Berridge $\mathrm{CW}$, et al. Experimental strategies for investigating psychostimulant drug actions and prefrontal cortical function in ADHD and related attention disorders. Anat Rec (Hoboken) 2011;294:1698-712.

18. Noto H, Roppolo JR, Steers WD, de Groat WC. Electrophysiologi$\mathrm{cal}$ analysis of the ascending and descending components of the micturition reflex pathway in the rat. Brain Res 1991;549:95-105.

19. Yoshimura N, Chancellor MB. Neurophysiology of lower urinary tract function and dysfunction. Rev Urol 2003;5 Suppl 8:S3-10.

20. Zhang H, Reitz A, Kollias S, Summers P, Curt A, Schurch B. An fMRI study of the role of suprapontine brain structures in the voluntary voiding control induced by pelvic floor contraction. Neuroimage 2005;24:174-80.

21. Blok BF, Holstege G. Two pontine micturition centers in the cat are not interconnected directly: implications for the central organization of micturition. J Comp Neurol 1999;403:209-18.
22. Mallory BS, Roppolo JR, de Groat WC. Pharmacological modulation of the pontine micturition center. Brain Res 1991;546:310-20.

23. Corbett A, McGowin A, Sieber S, Flannery T, Sibbitt B. A method for reliable voluntary oral administration of a fixed dosage $(\mathrm{mg} / \mathrm{kg})$ of chronic daily medication to rats. Lab Anim 2012;46:318-24.

24. Leach MC, Forrester AR, Flecknell PA. Influence of preferred foodstuffs on the antinociceptive effects of orally administered buprenorphine in laboratory rats. Lab Anim 2010;44:54-8.

25. Lee T, Yoon SM. The role of intra-abdominal pressure measurement in awake rat cystometry. Int Neurourol J 2013;17:44-7.

26. Chertin B, Koulikov D, Abu-Arafeh W, Mor Y, Shenfeld OZ, Farkas A. Treatment of nocturnal enuresis in children with attention deficit hyperactivity disorder. J Urol 2007;178(4 Pt 2):1744-7.

27. Kaye JD, Palmer LS. Characterization and management of voiding dysfunction in children with attention deficit hyperactivity disorder. Urology 2010;76:220-4. 